\title{
Effect of different photo-initiators and light curing units on degree of conversion of composites
}

\section{William Cunha Brandt ${ }^{(a)}$ Luis Felipe Jochims Schneider ${ }^{(b)}$ Elisabete Frollini(c) Lourenço Correr-Sobrinho(d) Mário Alexandre Coelho Sinhoreti ${ }^{(d)}$}

\footnotetext{
(a) MSc, PhD Student in Dental Materials; (d) PhD, Professor - Department of Restorative Dentistry, Dental Materials Area, Piracicaba Dental School, State University of Campinas, São Paulo, Brazil.

(b) PhD, Professor, Department of Restorative Dentistry, School of Dentistry, University of Passo Fundo, Passo Fundo, Rio Grande do Sul, Brazil.

(c) PhD, Professor, São Carlos Chemistry Institute, São Paulo University, São Carlos, São Paulo, Brazil.
}

\begin{abstract}
The aim of this study was to evaluate: (i) the absorption of photo-initiators and emission spectra of light curing units (LCUs); and (ii) the degree of conversion (DC) of experimental composites formulated with different photo-initiators when activated by different LCUs. Blends of BisGMA, UDMA, BisEMA and TEGDMA with camphorquinone (CQ) and/ or 1-phenyl-1,2-propanedione (PPD) were prepared. Dimethylaminoethyl methacrylate (DMAEMA) was used as co-initiator. Each mixture was loaded with $65 \mathrm{wt} \%$ of silanated filler particles. One quartz-tungsten-halogen - QTH (XL 2500, 3M/ESPE) and two lightemitting diode (LED) LCUs (UltraBlue IS, DMC and UltraLume LED 5, Ultradent) were used for activation procedures. Irradiance $\left(\mathrm{mW} / \mathrm{cm}^{2}\right)$ was calculated by the ratio of the output power by the area of the tip, and spectral distribution with a spectrometer (USB 2000). The absorption curve of each photo-initiator was determined using a spectrophotometer (Varian Cary 5G). DC was assessed by Fourier transformed infrared spectroscopy. Data were submitted to two-way ANOVA and Tukey's test $(5 \%)$. No significant difference was found for DC values when using LED LCUs regardless of the photo-initiator type. However, PPD showed significantly lower DC values than composites with CQ when irradiated with QTH. PPD produced DC values similar to those of CQ, but it was dependent on the LCU type.
\end{abstract}

Descriptors: Composite resins; Curing lights, dental; Dental materials.

\section{Introduction}

Since the introduction of visible-light activated composites camphorquinone (CQ) has been widespread used as the principal photo-initiator molecule. ${ }^{1,2}$ However, CQ is a solid yellow compound and large amounts of it in resin formulations might lead to undesirable yellowing, which affects the final esthetic appearance of the cured material. ${ }^{3-5}$ Thus, researchers have tested different photo-initiators in the organic matrix to substitute, or act synergistically with CQ.4,6-8

The 1-Phenyl-1,2- Propanedione (PPD) has been suggested as a way to improve the polymerization kinetics and to reduce the "yellowing effect" of the photo-initiator. The absorption peak of this molecule is mainly in the near UV-Vis region and extends slightly into the visible region. ${ }^{9}$ However, many LCUs are available on the market and each one emits light in different regions of the spectrum. Therefore, there could not be 
a suitable correlation between the absorption spectra of the photo-initiators and the emission spectrum of the LCUs. Quartz-tungsten-halogen (QTH) LCUs have several drawbacks when compared with the light-emitting diodes (LEDs), ${ }^{10}$ such as relatively shorter efficient working life span; heat production and filters degradation with time. However, due to the narrow emission spectrum by second generation LEDs, some photo-initiators present in composites might not be activated. Therefore, LEDs that emit wider spectrum have been developed. ${ }^{11}$

Due to the lack of outcomes regarding the use of different photo-initiator systems combined with different LCUs, it is necessary to evaluate the effect of these factors on the resultant polymer properties. Therefore, the specific aims of this study were:

1. to evaluate the absorption of photo-initiators and emission spectra of light curing units; and

2. to evaluate the degree of conversion (DC), which determines the final properties of composites; ${ }^{12}$ of experimental composites with different photoinitiators, photo-activated by LEDs and QTH.

The hypotheses tested were that:

1. PPD could produce polymers with DC values similar to those produced by CQ, regardless of the LCU tested;

2. the use of LED with wider emission spectrum generates the highest $\mathrm{DC}$ values regardless of the photo-initiator type; and

3. the association PPD/CQ could produce polymers with higher DC than that of each photo-initiator by itself, regardless of the LCU tested.

\section{Material and Methods Resin preparation}

Three experimental composite formulations were tested in this study. The resin matrix for all for- mulations consisted of a combination of bisphenol glycidyl methacrylate - $29.0 \mathrm{wt} \%$ (BisGMA - Sigma-Aldrich Inc., St. Louis, MO, USA), urethane dimethacrylate - $32.5 \mathrm{wt} \%$ (UDMA - Sigma-Aldrich Inc., St. Louis, MO, USA), bisphenol ethoxylate dimethacrylate - $32.5 \mathrm{wt} \%$ (BisEMA - Sigma-Aldrich Inc., St. Louis, MO, USA) and triethyleneglycol dimethacrylate - $6.0 \mathrm{wt} \%$ (TEGDMA - Sigma-Aldrich Inc., St. Louis, MO, USA). Composites were loaded with $65 \mathrm{wt} \%$ silanated filler (20 wt\% silica with $0.04 \mu \mathrm{m}$ and $80 \mathrm{wt} \%$ Ba-Al-silicate glass with $0.5 \mu \mathrm{m}$ - FGM, Joinville, SC, Brazil).

The only difference among the composites was the photo-initiator system (Camphorquinone - CQ or 1-Phenyl-1,2-Propanedione; Sigma-Aldrich Inc., St. Louis, MO, USA), whereas dimethylaminoethyl methacrylate (DMAEMA - Sigma-Aldrich Inc., St. Louis, MO, USA) was always used as co-initiator. Therefore, the following photo-initiator systems were tested:

a. CQ $(0.4 \mathrm{wt} \%)$ and DMAEMA (0.8 wt $\%)$;

b. PPD (0.4 wt $\%)$ and DMAEMA $(0.8 \mathrm{wt} \%)$; and

c. CQ $(0.2 \mathrm{wt} \%)+$ PPD $(0.2 \mathrm{wt} \%)$ and DMAEMA $(0.8 \mathrm{wt} \%)$.

\section{Light curing units}

Table 1 gives details of the LCUs used in the study. The diameter of the LCU tips was standardized at $7 \mathrm{~mm}$ by using a black cover with circular hole in the middle. Subsequently, the output power $(\mathrm{mW})$ of each LCU was measured with a calibrated power meter (Ophir Optronics, Har-Hotzvim, Jerusalém, Israel). Thus, the light irradiance $\left(\mathrm{mW} / \mathrm{cm}^{2}\right)$ was determined by dividing the output power by the tip area.

Spectral distributions were obtained by using a calibrated spectrometer (USB2000, Ocean Optics,

\begin{tabular}{c|c|c|c|c|c|c}
$\begin{array}{c}\text { Table 1 - LCUs } \\
\text { used in the study. }\end{array}$ & LCU & Manufacturer & Type & $\begin{array}{c}\text { Tip diameter } \\
(\mathrm{mm})\end{array}$ & $\begin{array}{c}\text { Irradiance } \\
\left(\mathrm{mW} / \mathrm{cm}^{2}\right)\end{array}$ & $\begin{array}{c}\text { Radiant exposure } \\
\left(\mathrm{J} / \mathrm{cm}^{2}\right)\end{array}$ \\
\cline { 2 - 6 } & XL 2500 & 3M/ESPE, St. Paul, MN, USA & QTH & 7 & 935 & 35.5 \\
\hline UltraBlue IS & $\begin{array}{r}\text { DMC Equip, São Carlos, } \\
\text { SP, Brazil }\end{array}$ & LED & 7.5 & 597 & 35.8 \\
\hline $\begin{array}{c}\text { UltraLume } \\
\text { LED 5 }\end{array}$ & $\begin{array}{c}\text { Ultradent Products Inc., } \\
\text { South Jordan, Utah, USA }\end{array}$ & LED & $11 \times 7$ & 1,315 & 35.5 \\
\hline
\end{tabular}


Dunedin, FL, USA). The irradiance and the spectral distribution data were integrated using the Origin 6.0 software (OriginLab Northampton, MA, USA).

All LCUs were analyzed with the standardization of the tip, for the complete certainty that the black cover would not affect the quality of light emission, mainly of Ultra Lume LED 5.

\section{Photo-initiators}

The photo-initiators CQ (Sigma-Aldrich Inc., St. Louis, MO, USA) and PPD (Sigma-Aldrich Inc., St. Louis, MO, USA) were used as received. Absorption spectra were determined using a UV-Vis spectrophotometer (Varian Cary 5G, Sidney, New South Wales, Australia). Only the visible and near UV range was of interest $(350-550 \mathrm{~nm})$, as this range reflects the emission of most LCUs. Absorption spectra were recorded for each photo-initiator separately (CQ and PPD).

\section{Degree of conversion}

The composite prepared for FTIR spectroscopy analysis (Bomem, model MB-102, Montreal, Quebec, Canada) was applied in a circular mold $(7 \mathrm{~mm}$ inner diameter and $1 \mathrm{~mm}$ height), and photo-activated. Photo-activation was performed using different times to maintain the radiant exposure (Table $1)$.

After $24 \mathrm{~h}$, at $37^{\circ} \mathrm{C}$ and light protected, each specimen was finely pulverized by using a hard tissue-grinding machine (Marconi, model MA590, Piracicaba, SP, Brazil). After that, $10 \mathrm{mg}$ of the ground powder was mixed with $100 \mathrm{mg}$ of $\mathrm{KBr}$ (Aldrich, Milwaukee, WI, USA) powder salt. This mixture was placed into a pelleting device (Aldrich, Milwaukee, WI, USA) and then pressed in a hydraulic press (Carver Laboratory Press, model 3648, Wabash, St. Morris, USA) with a load of 8 tons to obtain a pellet. This pellet was then placed in a holder attachment within the spectrophotometer (Bomem, model MB-102, Montreal, Quebec, Canada) for analysis. The uncured composite was analyzed using a metal siliceous window.

The measurements were recorded in absorbance mode with a FTIR spectrometer (Bomem, model MB-102, Montreal, Quebec, Canada) operating un- der the following conditions: $300-4000 \mathrm{~cm}^{-1}$ wavelength; $4 \mathrm{~cm}^{-1}$ resolution; 32 scans. The percentage of unreacted carbon-carbon double bonds $(\mathrm{C}=\mathrm{C})$ was determined from the ratio of absorbance intensities of aliphatic $\mathrm{C}=\mathrm{C}$ (peak at $1638 \mathrm{~cm}^{-1}$ ) against the internal standard (aromatic C-C, peak at $1608 \mathrm{~cm}^{-1}$ ) before and after curing the specimen. The degree of conversion was determined by subtracting the $\%$ $\mathrm{C}=\mathrm{C}$ from $100 \%$. All experiments were carried out in triplicate.

\section{Statistical analysis}

Data was statistically evaluated using a two-way analysis of variance (ANOVA). Comparisons were conducted using Tukey's test $(p \leq 0.05)$.

\section{Results}

\section{Photo-initiators and Light Curing Units}

The spectra of the photo-initiators and LCUs used in this study are shown in Graph 1. The UltraLume 5 showed the highest irradiance values $\left(1315 \mathrm{~mW} / \mathrm{cm}^{2}\right)$, with emission peak at $454 \mathrm{~nm}$, whereas UltraBlue IS presented the lowest irradiance values $\left(597 \mathrm{~mW} / \mathrm{cm}^{2}\right)$, with emission peak at $456 \mathrm{~nm}$. XL 2500 showed intermediary values $\left(935 \mathrm{~mW} / \mathrm{cm}^{2}\right)$, with emission peak at $484 \mathrm{~nm}$. The light absorption analysis of dental photo-initiators showed that CQ exhibited an absorption centered in the blue region of the light spectrum, with $\mathrm{Abs}_{\max }$ at $470 \mathrm{~nm}$, while PPD initiates the curve in the UV

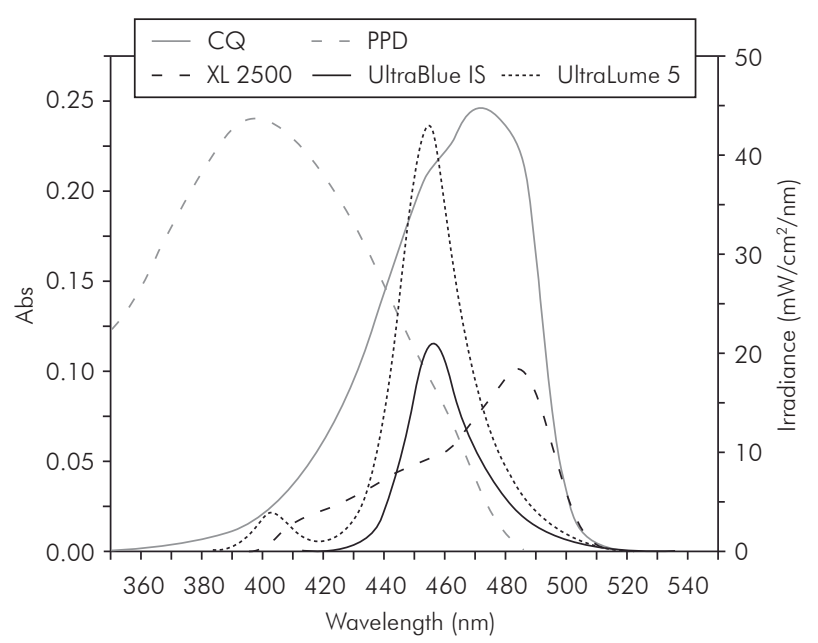

Graph 1 - LCUs and photo-initiators spectra. 
region, with $\mathrm{Abs}_{\max }$ at $398 \mathrm{~nm}$; its absorption extended into the visible region.

\section{Degree of conversion}

Table 2 shows the mean DC values of composites formulated with different types of photo-initiator (CQ, PPD or CQ/PPD) when photo-activated by the three different light curing units. DC for composites formulated with CQ and CQ/PPD was not dependent on the LCU used. However, UltraLume 5 LED promoted higher DC than XL2500 for material containing PPD only. UltraBlue IS did not differ from the others. When XL2500 was used, composite formulated with CQ presented higher DC than those with PPD or CQ/PPD, which did not differ between them. With UltraBlue IS and UltraLume 5 LCUs there were no significant differences among the three types of photo-initiator.

\section{Discussion}

Most photo-initiators formulated for commercial dental resins consist of two-components:(i) the photo-initiator [typically a camphorquinone, (CQ)] which can absorb light directly and (ii) a co-initiator (typically an amine) that does not absorb light but interacts with the activated photo-initiator to generate a reactive free radical and initiates polymerization. CQ is a typical visible light-activated free radical photo-initiator with an absorbance range between 400 and $500 \mathrm{~nm}$. However, it has some drawbacks such as low polymerization efficiency, toxicity and may compromise the esthetics of dental composite restorations due to the influence of residual, un-reacted CQ molecules. ${ }^{13}$

PPD was chosen because it is also used in some dental composites, despite its light absorption peak at $398 \mathrm{~nm}$. Because of the latter, PPD is a better UV initiator than an efficient visible light photo-initiator. Even so, he is used in composite resins by possessing larger extinction coefficient that CQ. Extinction coefficient is the probability of light absorption by a molecule. ${ }^{9,14}$

Both of these photo-initiators (CQ and PPD) can be used without any co-initiator in light curable dental composites, but to decrease their concentrations they are used with different co-initiators. The reason is simply that too high of a photo-initiator concentration affects the color of the dental composite. Therefore, to enhance the photo-initiator efficiency at lower concentrations, different co-initiators are added. . $^{3,7,13,15}$

The co-initiator (DMAEMA) was used in the proportion 2:1 (co-initiator / photo-initiator, respectively) in agreement with other studies that found larger degree of conversion values in that proportion, when DMAEMA was used with CQ. ${ }^{16-17}$ When the amine concentration is lower than that of CQ, the spontaneous collision of the two substances becomes difficult owing to the small quantity of amine in the reaction. In this case, some molecules of CQ in triplet state return to their fundamental state, reducing the generation of free radicals. When the amine concentration is higher than that of CQ, the production of radicals depends solely on the reactivity of the system, since the collision of molecules will occur because of the excess of amine. ${ }^{18}$ That is why the amine was also used with the PPD, so that a comparison of the two photoinitiators in the same conditions could be made, even if it favored CQ. That way, if the PPD obtained good results, it could be an alternative to CQ.

Degree of conversion is an important parameter influencing the final physical and biological properties of composites. ${ }^{19-20}$ Lower conversion values may

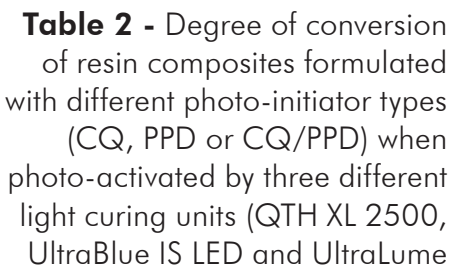

5 LED).

\begin{tabular}{c|c|c|c|c|c|c}
\hline \multirow{2}{*}{$\begin{array}{c}\text { Composites with } \\
\text { photoinitiators }\end{array}$} & \multicolumn{2}{|c|}{ XL2500 } & \multicolumn{2}{c|}{ UltraBlue IS } & \multicolumn{2}{c}{ UltraLume 5 } \\
\cline { 2 - 7 } & $\mathrm{DC} \%$ & $\mathrm{sd}$ & $\mathrm{DC} \%$ & $\mathrm{sd}$ & $\mathrm{DC} \%$ & $\mathrm{sd}$ \\
\hline $\mathrm{CQ}$ & $65.1 \mathrm{~A}, \mathrm{a}$ & 0.6 & $62.8 \mathrm{~A}, \mathrm{a}$ & 1.4 & $63.0 \mathrm{~A}, \mathrm{a}$ & 1.6 \\
\hline $\mathrm{PPD}$ & $58.8 \mathrm{~B}, \mathrm{~b}$ & 1.8 & $61.6 \mathrm{~A}, \mathrm{ab}$ & 0.6 & $62.9 \mathrm{~A}, \mathrm{a}$ & 2.0 \\
\hline $\mathrm{CQ} / \mathrm{PPD}$ & $61.4 \mathrm{~B}, \mathrm{a}$ & 2.1 & $60.9 \mathrm{~A}, \mathrm{a}$ & 1.2 & $62.6 \mathrm{~A}, \mathrm{a}$ & 0.5 \\
\hline
\end{tabular}

Means followed by different capital letters in the same column, and small letters in the same line, were significantly different $(p<0.05)$. 
also result in a depletion of leachable, unreached material at the restoration surface, increasing the biological impact of the material. ${ }^{21}$ This study evaluated the emission of LCUs and the absorption spectra of photo-initiators in order to determine the influence of the relationship between LCUs and spectra of the photo-initiators on the final DC of dental composites.

According to the FTIR analyses, both the LEDs were capable of activating the initiation process for all materials, irrespective of the photo-initiator type. However, when the QTH LCU was used, composite formulated with PPD produced a lower DC than that achieved with CQ. Consequently, the first and the second hypotheses were rejected, since the QTH produced lower DC values for PPD, and the UltraLume 5 produced the same DC values as those of the other LCUs for composites formulated with CQ and PPD.

Because UltraBlue IS's light emission peak is shifted $(456 \mathrm{~nm})$, it presented a good correlation with PPD. It might be suggested that its higher light output in shorter wavelengths $(456 \mathrm{~nm})$ entails a larger availability of photons in the higher energy absorption region of the PPD photo-initiator, thus contributing to produce better conversion results than those obtained by using a conventional QTH LCU.

Based on the spectral analyses of the LCUs, it was possible to verify that the light emission in wavelengths below $470 \mathrm{~nm}$ (which is the area where PPD absorbs more light) was around $472 \mathrm{~mW} / \mathrm{cm}^{2}$ of a total of $935 \mathrm{~mW} / \mathrm{cm}^{2}$ for XL 2500, $466.3 \mathrm{~mW} /$ $\mathrm{cm}^{2}$ of a total of $597 \mathrm{~mW} / \mathrm{cm}^{2}$ for UltraBlue IS, and $1,102 \mathrm{~mW} / \mathrm{cm}^{2}$ of a total of $1,315 \mathrm{~mW} / \mathrm{cm}^{2}$ for UltraLume 5. These light irradiance values represent $50.5 \%, 78.1 \%$, and $83.8 \%$, respectively, of the total irradiance emitted from each LCU, showing that the LEDs emit a larger amount of light in the area of the spectrum where PPD absorbs light than the QTH LCU. These outcomes corroborate the DC results, in which higher values were produced by the LED LCUs than QTH for the formulation with PPD. Neumann et al. ${ }^{22}$ (2005) also found better correlation of spectra between PPD and a LED LCU than with a QTH LCU.
The radiant exposure (defined as irradiance $x$ time) of each LCU in the area of the spectrum below $470 \mathrm{~nm}$ was $17.9 \mathrm{~J} / \mathrm{cm}^{2} ; 28 \mathrm{~J} / \mathrm{cm}^{2}$ and $29.8 \mathrm{~J} / \mathrm{cm}^{2}$ for XL 2500, UltraBlue IS and UltraLume 5, respectively (Graph 2). These results show that even when maintaining the total radiant exposure constant (in the present study it was maintained at approximately $35.5 \mathrm{~J} / \mathrm{cm}^{2}$ ) different results will be found in different areas of the spectrum due to the different emission profiles of each LCU. Therefore, although radiant exposure has enormous importance, ${ }^{23}$ the correlation between the absorption spectrum of the photo-initiator and the emission spectrum of the LCU also plays an essential role. Previous studies show similar outcomes. For example, Stahl et al. ${ }^{24}$ (2000) analyzed two LCUs: a QTH and a LED, and found that both produced similar flexural strength and flexural modulus despite LED emitting irradiance values 2.2 times lower than that of QTH.

Although QTH demonstrates a wider spectrum than LED UltraBlue IS, the latter emits higher irradiance values than the former in the area below $470 \mathrm{~nm}$. This implicates higher number of photons available in the area of major absorption by the PPD molecules, contributing to better DC results when this light is used. UltraLume 5 has a wide spectrum of light emission due to the presence of additional LEDs that emit light in the UV-Vis area (the smaller peak), with maxim light emission at $454 \mathrm{~nm}$.

According to the results of the present study, the

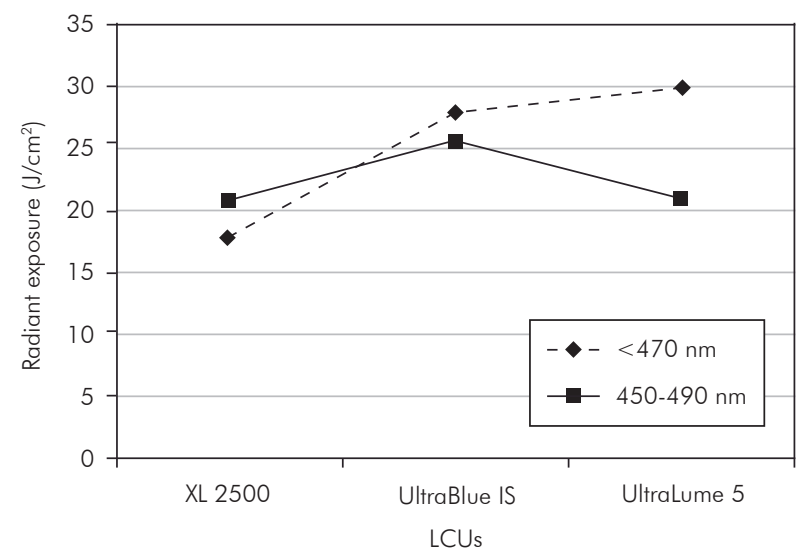

Graph 2 - Radiant exposure for LCUs in the better spectral regions for absorption of photo-initiator CQ (450-490 nm) and PPD (<470 $\mathrm{nm})$. 
DC produced by the formulation containing CQ was not dependent on the LCU used for lighting. This is probably because the radiant exposure values in the $450-490 \mathrm{~nm}$ range, which is the area of major absorption by $\mathrm{CQ},{ }^{25,26}$ was very similar among the LCUs tested $\left(20.8 \mathrm{~J} / \mathrm{cm}^{2} ; 25.7 \mathrm{~J} / \mathrm{cm}^{2}\right.$ and $21.1 \mathrm{~J} / \mathrm{cm}^{2}$ for XL 2500, UltraBlue IS and UltraLume 5, respectively). (Graph 2)

In addition to the correlation between LCU and photo-initiator, the differences in the generation of free radicals can also influence the values of DC. Without amine co-initiators, the CQ photo-decomposes slower than PPD probably due to the different mechanisms of free-radical development. For PPD, the photolysis of diketone leads to the cleavage of the $\mathrm{C}-\mathrm{C}$ bond between the two carbonyl groups, resulting in two radicals. For CQ, the two carbonyl radicals are structurally bonded to each other and, consequently, the probability of recombination in CQ is greater than that in PPD. ${ }^{4} \mathrm{On}$ the other hand, the rate of free-radicals development for PPD is lower than that of CQ when amine coinitiators are added. ${ }^{6,27}$ Since the current study used an amine:photoinitiator proportion of the $2: 1$, the
CQ might have been benefited. PPD could be more efficient than CQ in forming radical species by the photocleavage pathway, whereas for CQ the action mechanism is an electron/proton transfer process. (Figure 1)

It was expected that the use of CQ and PPD together might produce the highest DC values, since they could use different mechanisms for free radical formation and because their combination might produce a wider absorption profile. ${ }^{4}$ However, the association of PPD with CQ did not produce higher DC values, but reduced DC when QTH was used. This result probably occurred due to the concentration of photo-initiator used. Park et al. ${ }^{4}$ (1999) found better results of DC when CQ and PPD were used in the proportion of 1:1. Although the authors used the same CQ:PPD ratio as in the current study, a much higher concentration was applied $(1.8 \mathrm{wt} \%$, while in this study it was $0.4 \mathrm{wt} \%)$. The authors reported that the mixture of CQ with PPD resulted in a final conversion greater than that measured by the same concentration of either photo-sensitizer used alone. However, the authors used N,N-cyanoethylmethylaniline co-initiator and a commercial halogen
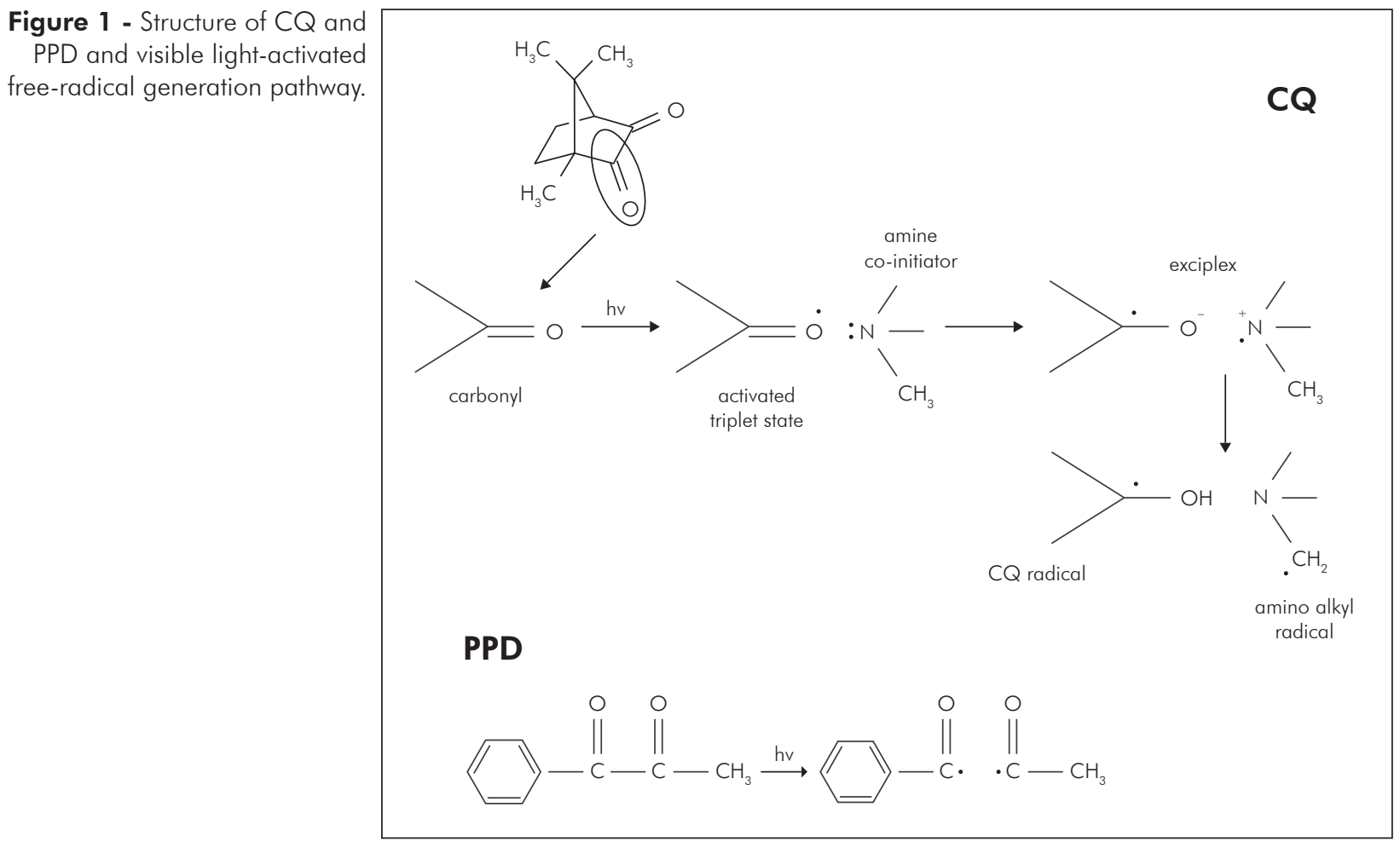
curing lamp which emits in the wavelength range 380-520 nm. Therefore, the synergistic effect of the CQ/PPD mixture reported by Park et al. ${ }^{4}$ (1999) may be attributed to the use of a more reactive co-initiator and a more efficient utilization of photon energy due to a larger overlap of the spectral distribution of the halogen curing lamp used by those authors with the combined photo-sensitizer absorption spectra. Consequently, the third hypothesis was rejected.

The results of this study showed that PPD has potential as an efficient visible light photo-sensitizer. However, it is dependent on the LCU used for photo-activation.

\section{Conclusion}

Considering the limitations of study, the three hypotheses were not accepted.

\section{References}

1. Taira M, Urabe H, Hirose T, Wakasa K, Yamaki M. Analysis of photo-initiators in visible-light-cured dental composite resins. J Dent Res. 1988 Jan;67(1):24-8.

2. Alvim HH, Alecio AC, Vasconcellos WA, Furlan M, de Oliveira JE, Saad JRC. Analysis of camphorquinone in composite resins as a function of shade. Dent Mater. 2007 Oct;23(10):1245-9.

3. Cook WD, Chong MP. Colour stability and visual perception of dimethacrylate based dental composite resins. Biomaterials. 1985 Jul;6(4):257-64.

4. Park YJ, Chae KH, Rawls HR. Development of a new photoinitiation system for dental light-cure composite resins. Dent Mater. 1999 Mar;15(2):120-7.

5. Ogunyinka A, Palin WM, Shortall AC, Marquis PM. Photoinitiation chemistry affects light transmission and degree of conversion of curing experimental dental resin composites. Dent Mater. 2007 Jul;23(7):807-13.

6. Sun GJ, Chae KH. Properties of 2,3-butanedione and 1-phenyl-1,2-propanedione as new photosensitizers for visible light cured dental resin composites. Polymer. 2000 Jul;41(16):620512.

7. Emami N, Soderholm KJ. Influence of light-curing procedures and photo-initiator/co-initiator composition on the degree of conversion of light-curing resins. J Mater Sci Mater Med. 2005 Jan;16(1):47-52.

8. Asmussen E, Peutzfeldt A. Influence of composition on rate of polymerization contraction of light-curing resin composites. Acta Odontol Scand. 2002 Jun;60(3):146-50.

9. Neumann MG, Schmitt CC, Ferreira GC, Correa IC. The initiating radical yields and the efficiency of polymerization
The photo-initiator PPD produced DC values similar to those produced by CQ when LEDs LCUs were used. When QTH LCU was used, the composite resin with PPD only had a smaller DC value. The use of LED with a wider emission spectrum (UltraLume LED 5) did not generate the highest DC values for the composite resins used, but the same DC values. The association PPD/CQ did not produce polymers with higher DC values than that of each photo-initiator by itself.

\section{Acknowledgements}

This study was supported by FAPESP (São Paulo Research Foundation), process number 07/51535-0. The first author also acknowledges FAPESP for financial support in the form of a scholarship.

for various dental photoinitiators excited by different light curing units. Dent Mater. 2006 Jun;22(6):576-84.

10. Bennett AW, Watts DC. Performance of two blue light-emitting-diode dental light curing units with distance and irradiation-time. Dent Mater. 2004 Jan;20(1):72-9.

11. Price RB, Felix CA, Andreou P. Evaluation of a dual peak third generation LED curing light. Compend Contin Educ Dent. 2005 May;26(5):331-2, 334, 336-8 passim; quiz 348.

12. Moraes RR, Brandt WC, Naves LZ, Correr-Sobrinho L, Piva E. Light- and time-dependent polymerization of dual-cured resin luting agent beneath ceramic. Acta Odontol Scand. 2008 Oct;66(5):257-61.

13. Park J, Ye Q, Topp EM, Misra A, Kieweg SL, Spencer P. Effect of photoinitiator system and water content on dynamic mechanical properties of a light-cured bisGMA/HEMA dental resin. J Biomed Mater Res A. 2010 Jun;15;93(4):1245-51.

14. Shin DH, Rawls HR. Degree of conversion and color stability of the light curing resin with new photoinitiator systems. Dent Mater. 2009 Aug;25(8):1030-8.

15. Musanje L, Ferracane JL, Sakaguchi RL. Determination of the optimal photoinitiator concentration in dental composites based on essential material properties. Dent Mater. 2009 Aug;25(8):994-1000.

16. Yoshida K, Greener EH. Effect of photoinitiator on degree of conversion of unfilled light-cured resin. J Dent. 1994 Oct;22(5):296-9.

17. Teshima W, Nomura Y, Tanaka N, Urabe H, Okazaki M; Nahara Y. ESR study of camphorquinone/amine photoinitiator systems using blue light-emitting diodes. Biomaterials. 2003; 24(12): 2097-103. 
18. Cook WD. Photopolymerization kinetics of dimethacrylates using the camphorquinone/amine initiator system. Polymer 1992; 33(3): 600-9.

19. Brandt WC, de Moraes RR, Correr-Sobrinho L, Sinhoreti MA, Consani S. Effect of different photo-activation methods on push out force, hardness and cross-link density of resin composite restorations. Dent Mater. 2008 Jun;24(6):84650.

20. Yap AU, Soh MS, Han TT, Siow KS. Influence of curing lights and modes on cross-link density of dental composites. Oper Dent. 2004 Jul-Aug;29(4):410-5.

21. Ferracane JL. Hygroscopic and hydrolytic effects in dental polymer networks. Dent Mater. 2006 Mar;22(3):211-22.

22. Neumann MG, Miranda WG, Jr., Schmitt CC, Rueggeberg FA, Correa IC. Molar extinction coefficients and the photon absorption efficiency of dental photoinitiators and light curing units. J Dent. 2005 Jul;33(6):525-32.
23. Fonseca RG, Santos JG, Adabo GL. Influence of activation modes on diametral tensile strength of dual-curing resin cements. Braz Oral Res. 2005 Oct-Dec;19(4):267-71.

24. Stahl F, Ashworth SH, Jandt KD, Mills RW. Light-emitting diode (LED) polymerisation of dental composites: flexural properties and polymerisation potential. Biomaterials. 2000 Jul;21(13):1379-85.

25 Nomoto R. Effect of light wavelength on polymerization of light-cured resins. Dent Mater J. 1997 Jun;16(1):60-73.

26 Micali B, Basting RT. Effectiveness of composite resin polymerization using light-emitting diodes (LEDs) or halogen-based light-curing units. Braz Oral Res. 2004 Jul-Sep;18(3):26670 .

27 Allen NS. Photoinitiators for UV and visible curing of coatings: Mechanisms and properties. J Photochem Photobiol A Chem. 1996 Oct 25;100(1-3):101-7. 